
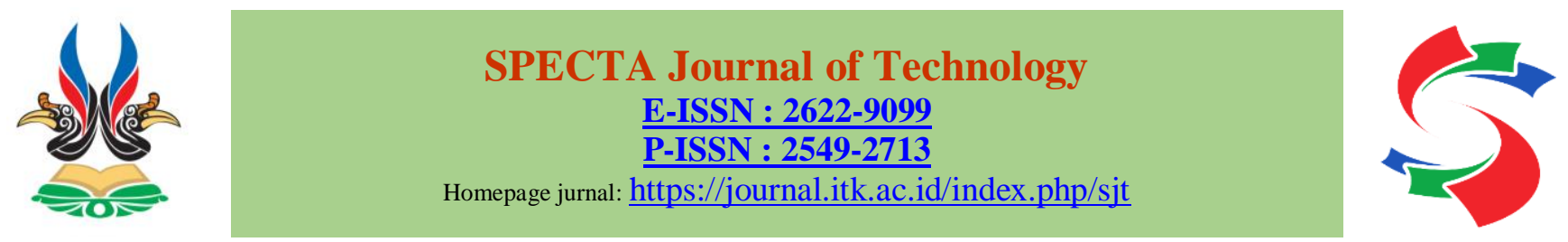

\title{
Optimization of Linear Quadratic Tracking (LQT) Weight Matrices Using Simulated Annealing Applied on Planar Arm Model
}

\author{
Dinita Rahmalia', Teguh Herlambang ${ }^{2}$, Sigit Pancahayani', Khozin Mu'tamar ${ }^{4}$ \\ ${ }^{1}$ Departement of Mathematics, Universitas Islam Darul Ulum, Lamongan. Email: dinitarahmalia@ gmail.com \\ ${ }^{2}$ Departement of Information System, Universitas Nahdlatul Ulama, Surabaya. Email: teguh@ unusa.ac.id \\ ${ }^{3}$ Departement of Mathematics, Institut Teknologi Kalimantan, Balikpapan. Email: spancahayani@itk.ac.id \\ ${ }^{4}$ Departement of Mathematics, Universitas Riau, Pekanbaru. Email: khozin.mutamar@unri.ac.id
}

\begin{abstract}
Optimal controls have been applied in this time. One of simple optimal control which will be analyzed in this research is planar arm model dynamic. The planar arm model dynamic consists of joint angles consisting of shoulder joint and elbow joint, angle velocities, and joint torquest due to passive muscle forces. There are control inputs from six muscles in the system. In this research, from planar arm model, it will be designed optimal control using Linear Quadratic Tracking (LQT). The objective function of planar arm model is we will minimimize two angles consisting of shoulder joint and elbow joint. In LQT, the value of performance index depends on the weight matrices so that we should optimize the weight matrices. In this research, the optimization of weight matrices in planar arm model will be applied by Simulated Annealing. The Simulated Annealing method is based on the simulation of thermal annealing of critically heated solids. Based on simulation results, Simulated Annealing can optimize the weight matrices in LQT so that it results optimal performance index with angle as state solution can follow the reference and we also obtain optimal controls from six muscle forces applied.
\end{abstract}

Keywords: linear quadratic tracking, optimal control, planar arm model, simulated annealing.

\begin{abstract}
Abstrak
Kontrol optimal telah banyak diaplikasikan pada saat ini. Salah satu dari kontrol optimal sederhana yang akan dianalisis dalam penelitian ini adalah model lengan pada bidang dua dimensi. Model lengan pada bidang dua dimensi terdiri dari sudut persendian yang terdiri dari persendian pada bahu dan siku, kecepatan sudut, dan torsi sendi pada gaya otot. Terdapat input kontrol dari enam otot pada sistem. Pada penelitian ini, akan dikonstruksi kontrol optimal menggunakan Linear Quadratic Tracking (LQT). Fungsi obyektif dari model ini adalah meminimumkan dua sudut persendian yang terdiri dari persendian pada bahu dan siku. Pada LQT, nilai dari performance index tergantung pada matriks bobot sehingga diperlukan optimisasi. Pada penelitian ini,optimisasi matriks bobot pada model lengan akan diaplikasikan menggunakan Simulated Annealing. Metode Simulated Annealing berdasarkan pada simulasi dari proses pemanasan dari logam. Berdasarkan hasil simulasi, Simulated Annealing dapat mengoptimisasi matriks bobot pada LQT sehingga menghasilkan nilai performance index yang optimal dengan sudut persendian dapat mengikuti reference dan hasil kontrol optimal dari enam otot akan diperoleh.
\end{abstract}

Kata Kunci: kontrol optimal, linear quadratic tracking, model lengan dua dimensi, simulated annealing. 


\section{Introduction}

Optimal controls have been applied in this time, such as in electronic devices or industrial devices. There are two types of control based on their properties i.e. open loop control and close loop control. Open loop control computes state solution without feedback while close loop control computes state solution with feedback (Ogata, 2002). One of simple optimal control which will be analyzed in this research is planar arm model dynamic.

The planar arm model dynamic consists of joint angles consisting of shoulder joint and elbow joint, angle velocities, and joint torquest due to passive muscle forces. There are six control inputs in the system. They are muscle force vector consisting of pectoralis major, posterior deltoid, brachialis, lateral head of triceps brachii, biceps brachii, and longhead of triceps.

In this research, from planar arm model, it will be designed optimal control using Linear Quadratic Tracking (LQT). The objective function of planar arm model is minimizing two angles consisting of shoulder joint and elbow joint. Moreover, there are six control inputs which will be determined in order that output of the system track or follow a desired trajectory that minimizes a performance index.

In LQT, the value of performance index depends on the weight matrices so that we should optimize the weight matrices. In previous researches, optimizations of weight matrices have been applied by Ant Colony Optimization (ACO) in inverted pendulum (Rahmalia, 2019) and optimal control of disease spread (Rahmalia, 2017), Particle Swarm Optimization (PSO) in Autonomous Underwater Vehicle (Herlambang, 2019). Besides that, the estimations of state solution have been applied by Kalman Filter on mobile robot trajectory (Herlambang, 2017), steam drum boiler system (Herlambang, 2018). In this research, the optimization of weight matrices in planar arm model will be applied by other method such as Simulated Annealing.

The Simulated Annealing method is based on the simulation of thermal annealing of critically heated solids. When a solid or metal is brought into a molten state by heating it to a high temperature, the atoms in the molten metal move freely with respect to each other. However, the movements of atoms get restricted as the temperature is reduced (Kirkpatrick, 1983).

Based on simulation results, we can conclude that Simulated Annealing can optimize the weight matrices in LQT so that it results optimal performance index with angle as state solution can follow the reference and we also obtain optimal controls from six muscle forces applied.

\section{Methods}

\subsection{State Space of Planar Arm Model}

The planar arm model dynamic can be seen in Figure 1. 

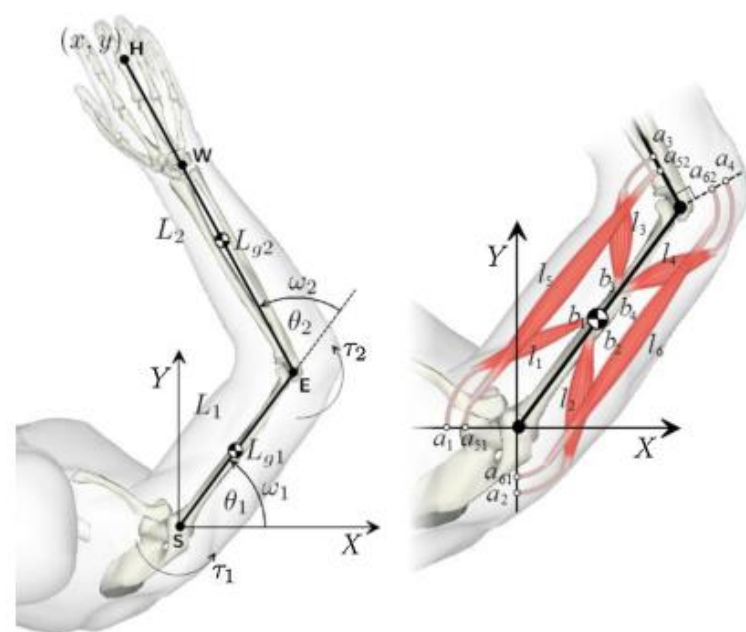

Figure 1: Planar Arm Model Dynamic

Source: Zasravec and Matjacic, 2013

The planar arm model dynamic consists of joint angles consisting of shoulder joint and elbow joint $\theta=\left[\begin{array}{l}\theta_{1} \\ \theta_{2}\end{array}\right]$, angle velocities $\dot{\theta}=\left[\begin{array}{l}\dot{\theta}_{1} \\ \dot{\theta}_{2}\end{array}\right]=\left[\begin{array}{l}\omega_{1} \\ \omega_{2}\end{array}\right]$, and joint torquest due to passive muscle forces $\tau_{\text {muscle }}=\left[\begin{array}{c}\tau_{1, \text { muscle }} \\ \tau_{2, \text { muscle }}\end{array}\right]$ which is given in Equation (1).

$$
M(\theta) \ddot{\theta}+C(\theta, \dot{\theta}) \dot{\theta}+B \dot{\theta}=\tau_{\text {muscle }}
$$

With $M$ is manipulator inertia value, $C$ is coriolis and centrifugal matrix and $B$ is viscosity matrix which can be expanded as follows (Zadravec, 2013):

$$
\begin{gathered}
M(\theta)=\left[\begin{array}{cc}
\alpha+2 \beta \cos \theta_{2} & \delta+\beta \cos \theta_{2} \\
\delta+\beta \cos \theta_{2} & \delta
\end{array}\right] \\
C(\theta, \dot{\theta})=\left[\begin{array}{cc}
-\beta \dot{\theta}_{2} \sin \theta_{2} & -\beta\left(\dot{\theta}_{1}+\dot{\theta}_{2}\right) \sin \theta_{2} \\
\beta \dot{\theta}_{1} \sin \theta_{2} & 0
\end{array}\right] \\
B=\left[\begin{array}{ll}
b_{11} & b_{12} \\
b_{21} & b_{22}
\end{array}\right] \\
\alpha=I_{1}+I_{2}+m_{1} L_{g 1}^{2}+m_{2}\left(L_{1}^{2}+L_{g 2}^{2}\right) \\
\beta=m_{2} L_{1}+L_{g 2} \\
\delta=I_{2}+m_{2} L_{g 2}^{2}
\end{gathered}
$$

So that the system in (1) becomes:

$$
\left[\begin{array}{cc}
\alpha+2 \beta \cos \theta_{2} & \delta+\beta \cos \theta_{2} \\
\delta+\beta \cos \theta_{2} & \delta
\end{array}\right]\left[\begin{array}{c}
\ddot{\theta}_{1} \\
\ddot{\theta}_{2}
\end{array}\right]+\left[\begin{array}{cc}
-\beta \dot{\theta}_{2} \sin \theta_{2} & -\beta\left(\dot{\theta}_{1}+\dot{\theta}_{2}\right) \sin \theta_{2} \\
\beta \dot{\theta}_{1} \sin \theta_{2} & 0
\end{array}\right]\left[\begin{array}{c}
\dot{\theta}_{1} \\
\dot{\theta}_{2}
\end{array}\right]+\left[\begin{array}{cc}
b_{11} & b_{12} \\
b_{21} & b_{22}
\end{array}\right]\left[\begin{array}{c}
\dot{\theta}_{1} \\
\dot{\theta}_{2}
\end{array}\right]=\tau_{\text {muscle }}
$$

There are six control inputs in the system which can be formed as follows: 


$$
\tau_{\text {muscle }}=W^{T} U=\left[\begin{array}{cccccc}
-a_{1} & a_{2} & 0 & 0 & -a_{51} & a_{61} \\
0 & 0 & -a_{3} & a_{4} & -a_{52} & a_{62}
\end{array}\right]\left[\begin{array}{c}
U_{1} \\
U_{2} \\
U_{3} \\
U_{4} \\
U_{5} \\
U_{6}
\end{array}\right]
$$

With $W^{T}$ is the moment lever matrix and $U_{1}, U_{2}, U_{3}, U_{4}, U_{5}, U_{6}$ are muscle force vector consisting of pectoralis major, posterior deltoid, brachialis, lateral head of triceps brachii, biceps brachii, and longhead of triceps.

By substituting $\theta=\left[\begin{array}{c}\theta_{1} \\ \theta_{2}\end{array}\right], \dot{\theta}=\left[\begin{array}{c}\dot{\theta}_{1} \\ \dot{\theta}_{2}\end{array}\right]=\left[\begin{array}{c}\omega_{1} \\ \omega_{2}\end{array}\right]$ and $\ddot{\theta}=\left[\begin{array}{c}\ddot{\theta}_{1} \\ \ddot{\theta}_{2}\end{array}\right]=\left[\begin{array}{c}\dot{\omega}_{1} \\ \dot{\omega}_{2}\end{array}\right]$, then the system in (2) becomes :

$$
\left[\begin{array}{cccc}
1 & 0 & 0 & 0 \\
0 & 1 & 0 & 0 \\
0 & 0 & \alpha+2 \beta \cos \theta_{2} & \delta+\beta \cos \theta_{2} \\
0 & 0 & \delta+\beta \cos \theta_{2} & \delta
\end{array}\right]\left[\begin{array}{c}
\dot{\theta}_{1} \\
\dot{\theta}_{2} \\
\dot{\omega}_{1} \\
\dot{\omega}_{2}
\end{array}\right]=\left[\begin{array}{cccc}
0 & 0 & 1 & 0 \\
0 & 0 & 0 & 1 \\
0 & 0 & \beta \omega_{2} \sin \theta_{2}-b_{11} & \beta\left(\omega_{1}+\omega_{2}\right) \sin \theta_{2}-b_{12} \\
0 & 0 & -\beta \omega_{1} \sin \theta_{2}-b_{21} & -b_{22}
\end{array}\right]\left[\begin{array}{c}
\theta_{1} \\
\theta_{2} \\
\omega_{1} \\
\omega_{2}
\end{array}\right]+\left[\begin{array}{cccccc}
0 & 0 & 0 & 0 & 0 & 0 \\
0 & 0 & 0 & 0 & 0 & 0 \\
-a_{1} & a_{2} & 0 & 0 & -a_{51} & a_{61} \\
0 & 0 & -a_{3} & a_{4} & -a_{52} & a_{62}
\end{array}\right]\left[\begin{array}{c}
U_{1} \\
U_{2} \\
U_{3} \\
U_{4} \\
U_{5} \\
U_{6}
\end{array}\right]
$$

Where state matrix and vector are:

$$
F=\left[\begin{array}{cccc}
1 & 0 & 0 & 0 \\
0 & 1 & 0 & 0 \\
0 & 0 & \alpha+2 \beta \cos \theta_{2} & \delta+\beta \cos \theta_{2} \\
0 & 0 & \delta+\beta \cos \theta_{2} & \delta
\end{array}\right]^{-1}\left(\left[\begin{array}{cccc}
0 & 0 & 1 & 0 \\
0 & 0 & 0 & 1 \\
0 & 0 & \beta \omega_{2} \sin \theta_{2}-b_{11} & \beta\left(\omega_{1}+\omega_{2}\right) \sin \theta_{2}-b_{12} \\
0 & 0 & -\beta \omega_{1} \sin \theta_{2}-b_{21} & -b_{22}
\end{array}\right]\left[\begin{array}{l}
\theta_{1} \\
\theta_{2} \\
\omega_{1} \\
\omega_{2}
\end{array}\right]\right)
$$

Input control matrix and vector are:

$$
G=\left[\begin{array}{cccc}
1 & 0 & 0 & 0 \\
0 & 1 & 0 & 0 \\
0 & 0 & \alpha+2 \beta \cos \theta_{2} & \delta+\beta \cos \theta_{2} \\
0 & 0 & \delta+\beta \cos \theta_{2} & \delta
\end{array}\right]^{-1}\left(\left[\begin{array}{ccccccc}
0 & 0 & 0 & 0 & 0 & 0 \\
0 & 0 & 0 & 0 & 0 & 0 \\
-a_{1} & a_{2} & 0 & 0 & -a_{51} & a_{61} \\
0 & 0 & -a_{3} & a_{4} & -a_{52} & a_{62}
\end{array}\right]\left[\begin{array}{c}
U_{1} \\
U_{2} \\
U_{3} \\
U_{4} \\
U_{5} \\
U_{6}
\end{array}\right]\right)
$$

because we will minimimize two angles then output matrix and vector are :

$$
Y=\left[\begin{array}{llll}
1 & 0 & 0 & 0 \\
0 & 1 & 0 & 0 \\
0 & 0 & 0 & 0 \\
0 & 0 & 0 & 0
\end{array}\right]\left[\begin{array}{l}
\theta_{1} \\
\theta_{2} \\
\omega_{1} \\
\omega_{2}
\end{array}\right]
$$

Because the system is nonlinear, we need to linearize state in (4) and input control in (5) using Jacobian matrix in Equation (7) and (8) respectively. 


$$
\begin{aligned}
& F_{x}=\left[\begin{array}{llll}
\frac{\partial F_{1}}{\partial \theta_{1}} & \frac{\partial F_{1}}{\partial \theta_{2}} & \frac{\partial F_{1}}{\partial \omega_{1}} & \frac{\partial F_{1}}{\partial \omega_{2}} \\
\frac{\partial F_{2}}{\partial \theta_{1}} & \frac{\partial F_{2}}{\partial \theta_{2}} & \frac{\partial F_{2}}{\partial \omega_{1}} & \frac{\partial F_{2}}{\partial \omega_{2}} \\
\frac{\partial F_{3}}{\partial \theta_{1}} & \frac{\partial F_{3}}{\partial \theta_{2}} & \frac{\partial F_{3}}{\partial \omega_{1}} & \frac{\partial F_{3}}{\partial \omega_{2}} \\
\frac{\partial F_{4}}{\partial \theta_{1}} & \frac{\partial F_{4}}{\partial \theta_{2}} & \frac{\partial F_{4}}{\partial \omega_{1}} & \frac{\partial F_{4}}{\partial \omega_{2}}
\end{array}\right] \\
& G_{u}=\left[\begin{array}{llllll}
\frac{\partial G_{1}}{\partial U_{1}} & \frac{\partial G_{1}}{\partial U_{2}} & \frac{\partial G_{1}}{\partial U_{3}} & \frac{\partial G_{1}}{\partial U_{4}} & \frac{\partial G_{1}}{\partial U_{5}} & \frac{\partial G_{1}}{\partial U_{6}} \\
\frac{\partial G_{2}}{\partial U_{1}} & \frac{\partial G_{2}}{\partial U_{2}} & \frac{\partial G_{2}}{\partial U_{3}} & \frac{\partial G_{2}}{\partial U_{4}} & \frac{\partial G_{2}}{\partial U_{5}} & \frac{\partial G_{2}}{\partial U_{6}} \\
\frac{\partial G_{3}}{\partial U_{1}} & \frac{\partial G_{3}}{\partial U_{2}} & \frac{\partial G_{3}}{\partial U_{3}} & \frac{\partial G_{3}}{\partial U_{4}} & \frac{\partial G_{3}}{\partial U_{5}} & \frac{\partial G_{3}}{\partial U_{6}} \\
\frac{\partial G_{4}}{\partial U_{1}} & \frac{\partial G_{4}}{\partial U_{2}} & \frac{\partial G_{4}}{\partial U_{3}} & \frac{\partial G_{4}}{\partial U_{4}} & \frac{\partial G_{4}}{\partial U_{5}} & \frac{\partial G_{4}}{\partial U_{6}}
\end{array}\right]
\end{aligned}
$$

\subsection{Linear Quadratic Tracking (LQT)}

The basic of Linear Quadratic Tracking (LQT) is output of the system track or follow a desired trajectory $r$ that minimizes a performance index $J$. LQT can be solved in either continuous time or discrete time.

LQT in continuous time can be constructed as follows :

$$
\begin{array}{cl}
\text { State equation } & : \dot{x}=A x(t)+B u(t) \\
\text { Output } & : y=C x(t) \\
\text { Performance index } & : \\
J=\frac{1}{2}(C x(T)-r e f(T))^{T} P(C x(T)-r e f(T))+\frac{1}{2} \int_{t=0}^{T}\left[(C x(t)-r e f(t))^{T} Q(C x(t)-r e f(t))+u(t)^{T} R u(t)\right] d t
\end{array}
$$

with $P \geq 0$ and $Q \geq 0$ are symmetric and positive semidefinite, also $R>0$ is symmeteric and positive definite.

The algorithm and computation of LQT in continuous time is as follows (Lewis, 2012):

1. Compute the solutions of Riccati matrix $S(t)=\left[\begin{array}{llll}s_{11} & s_{12} & s_{13} & s_{14} \\ s_{12} & s_{22} & s_{23} & s_{24} \\ s_{13} & s_{23} & s_{33} & s_{34} \\ s_{14} & s_{24} & s_{34} & s_{44}\end{array}\right], 0 \leq t<T_{f}$ which is symmetric and positive semidefinite. Solve them in backward.

$$
-\dot{S}=A^{T} S+S A-S B R^{-1} B^{T} S+C^{T} Q C, \text { with } S\left(T_{f}\right)=C^{T} P C
$$

2. Compute optimal feedback $K=R^{-1} B^{T} S$ 
3. Compute the solution $-\dot{v}=(A-B K)^{T} v+C^{T} Q . r e f$ with $v\left(T_{f}\right)=C^{T} P . r e f\left(T_{f}\right), 0 \leq t<T_{f}$ in backward time

4. Compute the solution $\dot{x}=A x+B\left(-K x+R^{-1} B^{T} v\right), 0<t \leq T_{f}$ in forward time

5. Compute optimal control $u=-K x+R^{-1} B^{T} v, 0 \leq t \leq T_{f}$

6. Compute performance index as objective function.

$$
J=\frac{1}{2}(C x(T)-r e f(T))^{T} P(C x(T)-r e f(T))+\frac{1}{2} \int_{t=0}^{T}\left[(C x(t)-r e f(t))^{T} Q(C x(t)-r e f(t))+u(t)^{T} R u(t)\right] d t
$$

The model of LQT in continous time also can be discretized by LQT in discrete time. The model of LQT in discrete time is defined as follows :

State equation $\dot{x}(t)$ and output $y(t)$ in discrete time can be constructed in (12) and (13) respectively.

$$
\begin{aligned}
& x_{k+1}=A x_{k}+B u_{k} \\
& y_{k}=C x_{k}
\end{aligned}
$$

and the Performance Index as objective function is defined as follows :

$$
J=\frac{1}{2} e_{N}^{T} P e_{N}+\frac{1}{2} \sum_{k=0}^{N-1}\left(e_{k}^{T} Q e_{k}+u_{k}^{T} R u_{k}\right)
$$

with $e_{N}=C x_{N}-r_{N}$ and $e_{k}=C x_{k}-r_{k}$

Error weighted matrices $P \geq 0$ and $Q \geq 0$ must be symmetric and positive semidefinite matrices, and control weighted matrix $R>0$ must be symmetric and positive definite matrix.

The algorithm and computation of LQT in discrete time is as follows (Naidu, 2003):

1. Compute $K_{k}, S_{k}, v_{k}, K_{k}^{v}$ backward with final conditions $S_{N}=C^{T} P C$ and $v_{N}=C^{T} P r_{N}$ are given.

For $k=(N-1): 0$

$$
\begin{aligned}
& K_{k}=\left(B^{T} S_{k+1} B+R\right)^{-1} B^{T} S_{k+1} A \\
& S_{k}=C^{T} Q C+A^{T} S_{k+1}\left(A-B K_{k}\right) \\
& v_{k}=\left(A-B K_{k}\right)^{T} v_{k+1}+C^{T} Q r_{k} \\
& K_{k}^{v}=\left(B^{T} S_{k+1} B+R\right)^{-1} B^{T}
\end{aligned}
$$

end

2. Compute $x_{k}$ forward with initial conditions $x_{0}$ are given.

For $k=0:(N-1)$

end

$$
x_{k+1}=A x_{k}+B\left(-K_{k} x_{k}+K_{k}^{v} v_{k+1}\right)
$$

3. Compute optimal control $u_{k}$

$$
u_{k}=-K_{k} x_{k}+K_{k}^{v} v_{k+1}
$$

4. Compute Performance Index $J$ as objective function 


$$
J=\frac{1}{2} e_{N}^{T} P e_{N}+\frac{1}{2} \sum_{k=0}^{N-1}\left(e_{k}^{T} Q e_{k}+u_{k}^{T} R u_{k}\right)
$$

with $e_{N}=C x_{N}-r_{N}$ and $e_{k}=C x_{k}-r_{k}$

\subsection{Simulated Annealing}

\subsubsection{The behavior of simulated annealing}

Simulated Annealing was discovered by Kirkpatrick in 1983. The Simulated Annealing method is based on the simulation of thermal annealing of critically heated solids. When a solid or metal is brought into a molten state by heating it to a high temperature, the atoms in the molten metal move freely with respect to each other. However, the movements of atoms get restricted as the temperature is reduced.

As the temperature reduces, the atoms tend to get ordered and finally form crystals having the minimum possible internal energy. The process of formation of crystals essentially depends on the cooling rate.

\subsubsection{Simulated annealing on Linear Quadratic Tracking ( $L Q T)$}

In LQT, the value of performance index is affected by weight matrices (Hassani, 2014 and Karthick, 2016). Generally, the elements of weight matrices are determined by trial and error so that in this research Simulated Annealing will be used for optimization. There are three weight matrices which will be optimized by Simulated Annealing such as : $P \geq 0, Q \geq 0$ and $R>0$.

By assuming $P=0, \quad Q=\left[\begin{array}{cccc}q_{11} & 0 & 0 & 0 \\ 0 & q_{22} & 0 & 0 \\ 0 & 0 & 0 & 0 \\ 0 & 0 & 0 & 0\end{array}\right], \quad R=\left[\begin{array}{cccccc}r_{11} & 0 & 0 & 0 & 0 & 0 \\ 0 & r_{22} & 0 & 0 & 0 & 0 \\ 0 & 0 & r_{33} & 0 & 0 & 0 \\ 0 & 0 & 0 & r_{44} & 0 & 0 \\ 0 & 0 & 0 & 0 & r_{55} & 0 \\ 0 & 0 & 0 & 0 & 0 & r_{66}\end{array}\right]$ because we will minimimize two angles $\theta=\left[\begin{array}{l}\theta_{1} \\ \theta_{2}\end{array}\right]$ and there are six control inputs $U_{1}, U_{2}, U_{3}, U_{4}, U_{5}, U_{6}$, then the decision variable used in Simulated Annealing is:

$$
X=\left[\begin{array}{llllllll}
q_{11} & q_{12} & r_{11} & r_{22} & r_{33} & r_{44} & r_{55} & r_{66}
\end{array}\right]
$$

with fitness value is performance index as objective function in Equation (21). The algorithm of Simulated Annealing can be constructed as follow (Rao, 2009):

For $t=1: t \max$.

For $k=1: k \max$.

1. Set current point $X_{i}^{k}(t)$ and current $f\left(X_{i}^{k}(t)\right)$

2. Generate new point $Y$ in the vicinity of $X$

$$
\begin{aligned}
& l b_{i}=X_{i}-v, \quad i=1,2, \ldots n \operatorname{dim} \\
& u b_{i}=X_{i}+v, \quad i=1,2, \ldots n \operatorname{dim} \\
& Y_{i}=l b_{i}+U(0,1)\left(u b_{i}-l b_{i}\right), \quad i=1,2, \ldots n \operatorname{dim}
\end{aligned}
$$

3. Compute $\Delta f=f\left(Y_{i}\right)-f\left(X_{i}^{k}(t)\right)$

4. If $\Delta f<0$

- Update current point with new point $X_{i}^{k+1}(t) \leftarrow Y_{i}$ else 
- Generate random variable $r \sim U(0,1)$

- Compute $P\left(Y_{i}\right)=e^{-\Delta f / B T}$ with Bolzmann constant $B=1$

if $r<P\left(Y_{i}\right)$

Update current point with new point $X_{i}^{k+1}(t) \leftarrow Y_{i}$

else

Set $X_{i}^{k+1}(t) \leftarrow X_{i}^{k}(t)$

end

end

end end

Reduce temperature $T \leftarrow c T, 0<c<1$

\section{Result and discussion}

The parameters used in planar arm model can be seen in Table 1 (Zadravec, 2013).

The parameters of moment lever matrix (in meter) used are (Zadravec, 2013):

$$
a_{1}=a_{2}=0.055 \quad a_{3}=a_{4}=0.045 \quad a_{51}=0.055 \quad a_{52}=0.045 \quad a_{61}=0.055 \quad a_{62}=0.045
$$

Three types simulations will be applied : LQT without tracking, LQT with constant tracking, and LQT with nonlinear tracking.

Table 1: Parameters of planar arm model

\begin{tabular}{lll}
\hline \multicolumn{1}{c}{ Parameters } & Notation & Value \\
\hline Length of shoulder joint $(\mathrm{m})$ & $L_{1}$ & 0.298 \\
Length of elbow joint $(\mathrm{m})$ & $L_{2}$ & 0.419 \\
Mass of shoulder joint $(\mathrm{kg})$ & $m_{1}$ & 2.089 \\
Mass of elbow joint $(\mathrm{kg})$ & $m_{2}$ & 1.912 \\
Center of mass of shoulder joint $(\mathrm{m})$ & $L_{g 1}$ & 0.152 \\
Center of mass of elbow joint $(\mathrm{m})$ & $L_{g 2}$ & 0.181 \\
Moment of inertia of shoulder joint $\left(\mathrm{kg} \mathrm{m}^{2}\right)$ & $I_{1}$ & 0.0159 \\
Moment of inertia of elbow joint $\left(\mathrm{kg} \mathrm{m}^{2}\right)$ & $I_{2}$ & 0.0257 \\
\hline
\end{tabular}

Source: Zasravec and Matjacic, 2013

\subsection{Linear Quadratic Tracking without Tracking}

Optimization of Simulated Annealing Process in LQT without tracking can be seen in Figure 2. In early iteration, the weight matrices as decision variable is still chosen randomly so that they produce large performance index as fitness value. When the temperature is reduced slowly, from Simulated Annealing results optimal weight matrices with value :

$q_{11}=1.0577 \quad q_{22}=1.2442$

$r_{11}=0.1259 \quad r_{22}=0.0051 \quad r_{33}=0.0393 \quad r_{44}=0.3044 \quad r_{55}=0.0236 \quad r_{66}=0.0002$

And the performance index as fitness value is 1.0448 . 


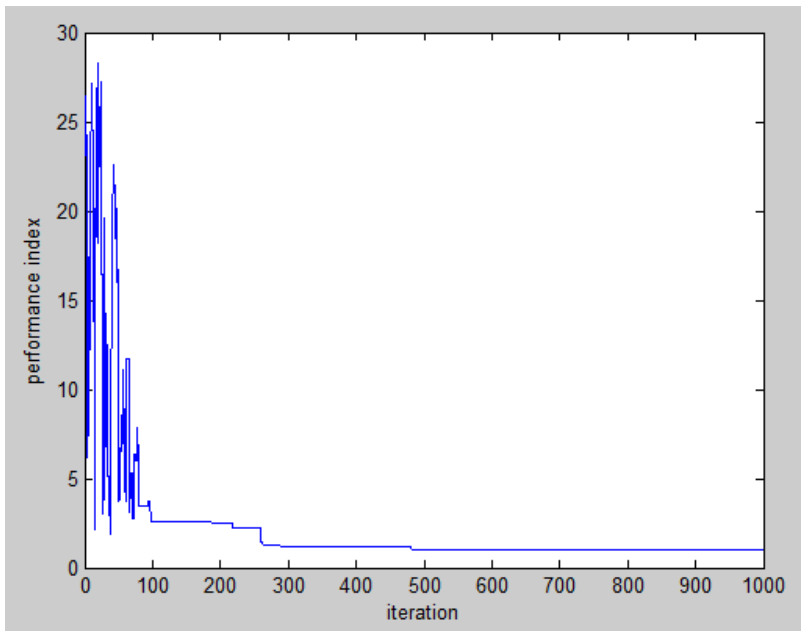

Figure 2: Optimization of Simulated Annealing Process in LQT without Tracking

When the optimal weight matrices are used in LQT simulation, the results can be seen in Figure 3 and Figure 4. Reference functions applied are :

$$
\begin{aligned}
& r e f\left(\theta_{1}\right)=0 \\
& \operatorname{ref}\left(\theta_{2}\right)=0
\end{aligned}
$$

Figure 3(a) is state solution of LQT without tracking in $\theta_{1}$ (angle of shoulder joint). Figure 3(b) is state solution of LQT without tracking in $\theta_{2}$ (angle of elbow joint). Both angle of shoulder joint and elbow joint can follow the reference function.

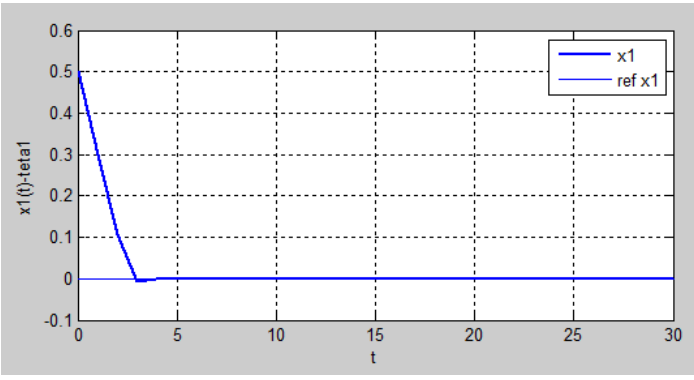

(a)

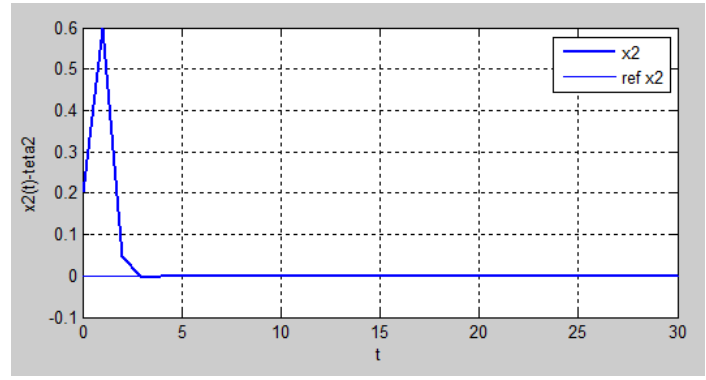

(b)

Figure 3: State solutions of LQT without Tracking (a) Angle 1 (b) Angle 2

Figure 4 shows the results of six optimal controls from six muscle force vectors (in Newton) such as pectoralis major $U_{1}$, posterior deltoid $U_{2}$, brachialis $U_{3}$, triceps brachii (lateral head) $U_{4}$, biceps brachii $U_{5}$, and triceps (longhead) $U_{6}$.
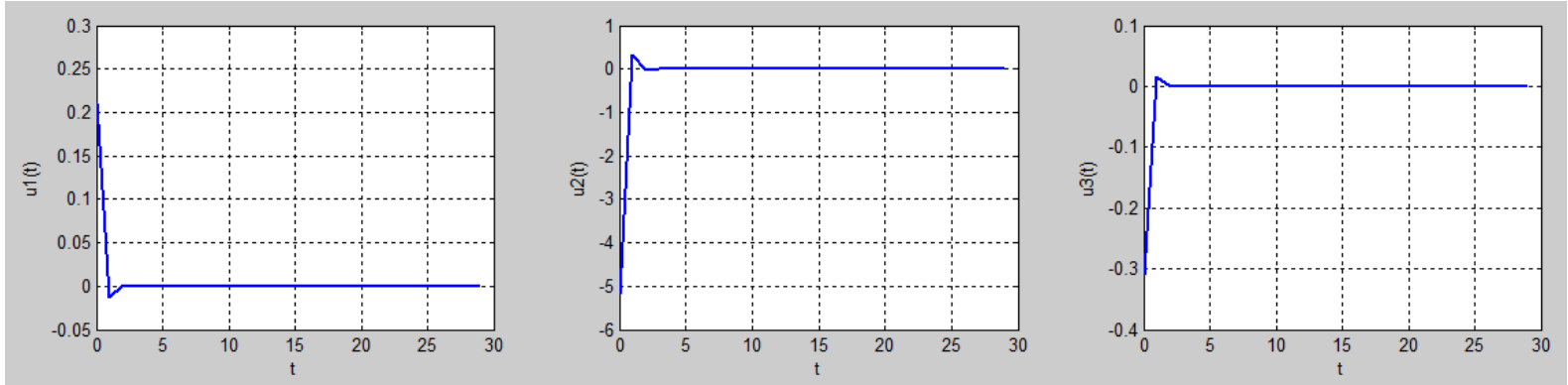

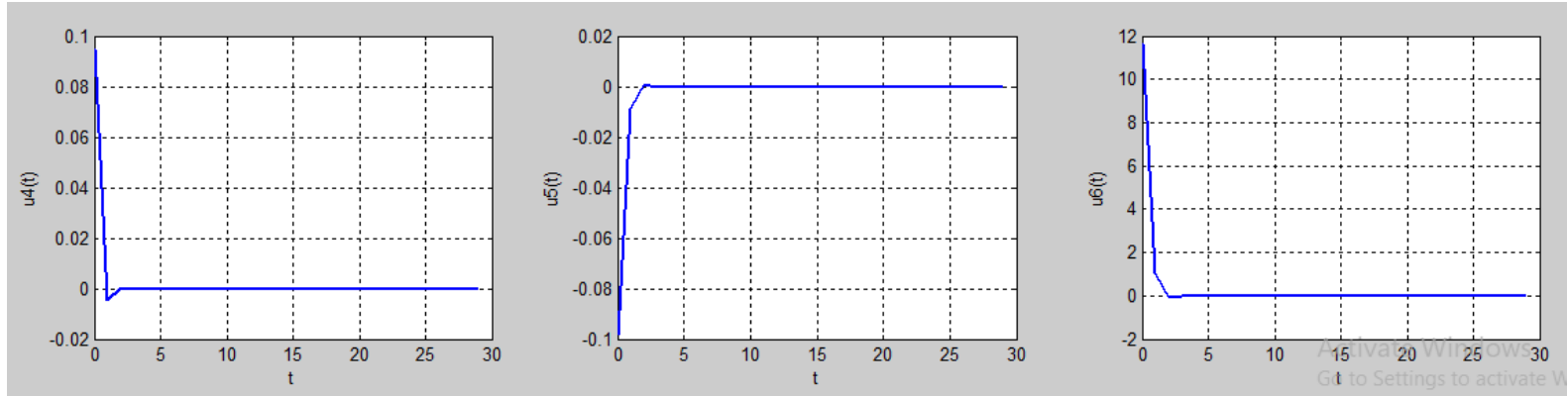

Figure 4: Six Optimal Controls from Six Muscle Force Vectors

\subsection{Linear Quadratic Tracking with Constant Tracking}

Optimization of Simulated Annealing Process in LQT with constant tracking can be seen in Figure 5. In early iteration, the weight matrices as decision variable is still chosen randomly so that they produce large performance index as fitness value. When the temperature is reduced slowly, from Simulated Annealing results optimal weight matrices with value :

$q_{11}=1.6626 \quad q_{22}=1.5187$

$r_{11}=0.0506 \quad r_{22}=0.3383 \quad r_{33}=0.0360 \quad r_{44}=0.1535 \quad r_{55}=0.1741 \quad r_{66}=0.0003$

And the performance index as fitness value is 36.8466 .

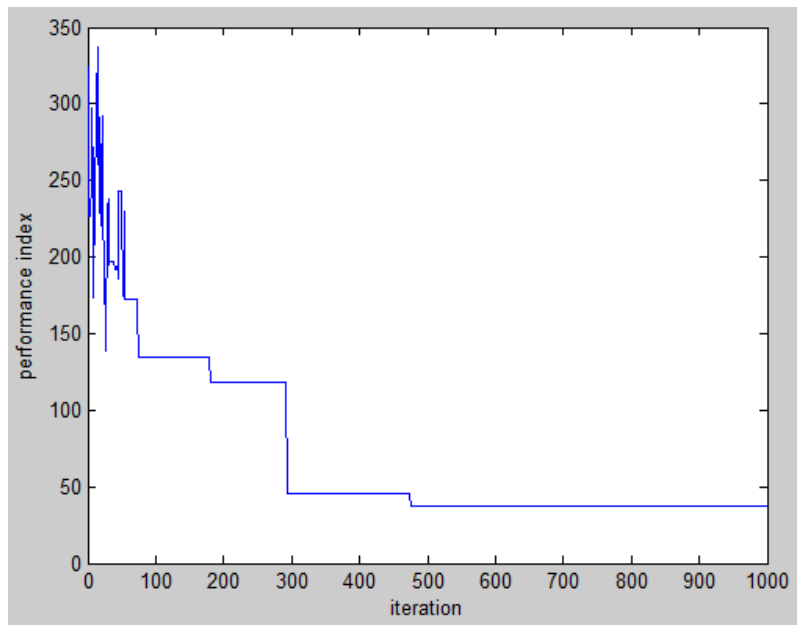

Figure 5: Optimization of Simulated Annealing Process in LQT with Constant Tracking

When the optimal weight matrices are used in LQT simulation, the results can be seen in Figure 6 and Figure 7. Reference functions applied are :

$$
\begin{gathered}
\operatorname{ref}\left(\theta_{1}\right)=2 \\
\operatorname{ref}\left(\theta_{2}\right)=1.5
\end{gathered}
$$

Figure 6(a) is state solution of LQT with constant tracking in $\theta_{1}$ (angle of shoulder joint). Figure 6(b) is state solution of LQT with constant tracking in $\theta_{2}$ (angle of elbow joint). Both angle of shoulder joint and elbow joint can follow the reference function. 


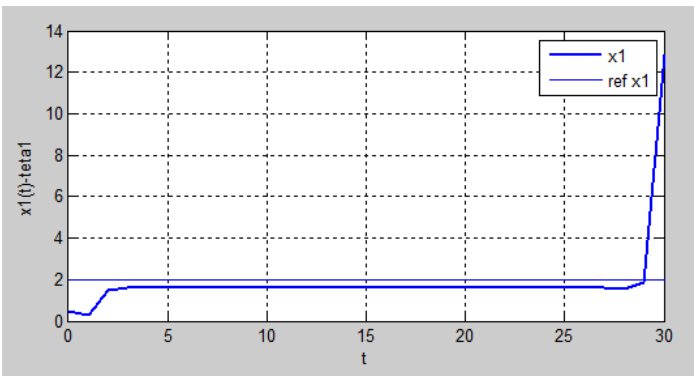

(a)

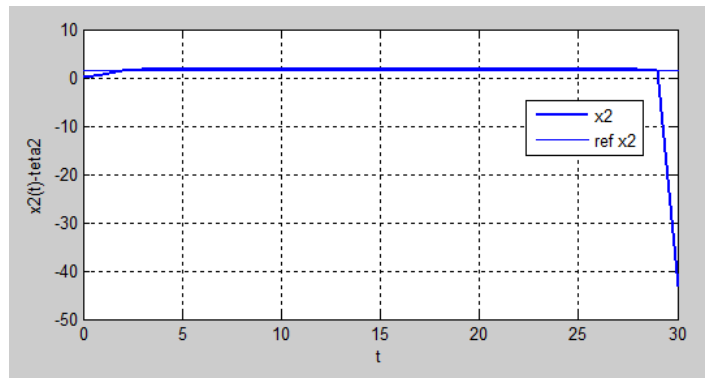

(b)

Figure 6: State Solutions of LQT with Constant Tracking (a) Angle 1 (b) Angle 2

Figure 7 shows the results of six optimal controls from six muscle force vectors (in Newton) such as pectoralis major $U_{1}$, posterior deltoid $U_{2}$, brachialis $U_{3}$, triceps brachii (lateral head) $U_{4}$, biceps brachii $U_{5}$, and triceps (longhead) $U_{6}$.

In about around of final time, there are deviations on the optimal controls and state solutions because there are no optimization process of weight matrix $P$ in the performance index and weight matrix $P$ is assumed by 0 .
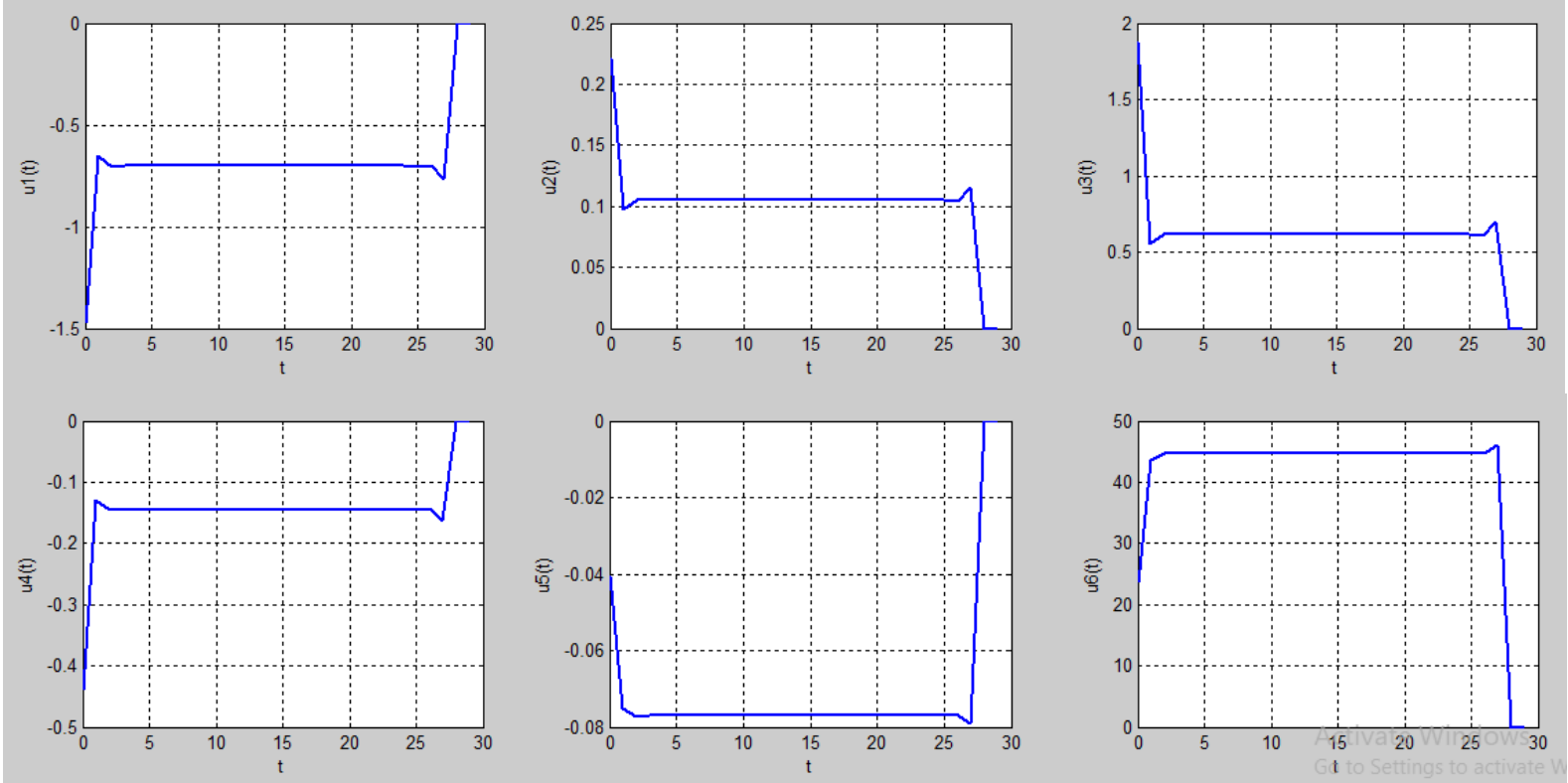

Figure 7: Six Optimal Controls from Six Muscle Force Vectors

\subsection{Linear Quadratic Tracking with Nonlinear Tracking}

Optimization of Simulated Annealing Process in LQT with nonlinear tracking can be seen in Figure 8. In early iteration, the weight matrices as decision variable is still chosen randomly so that they produce large performance index as fitness value. When the temperature is reduced slowly, from Simulated Annealing results optimal weight matrices with value :

$$
\begin{array}{llllll}
q_{11}=1.0282 & q_{22}=1.4139 \\
r_{11}=0.2710 & r_{22}=0.3123 & r_{33}=0.0002 & r_{44}=0.0546 & r_{55}=0.0818 \quad r_{66}=0.0048
\end{array}
$$

And the performance index as fitness value is 11.1586. 


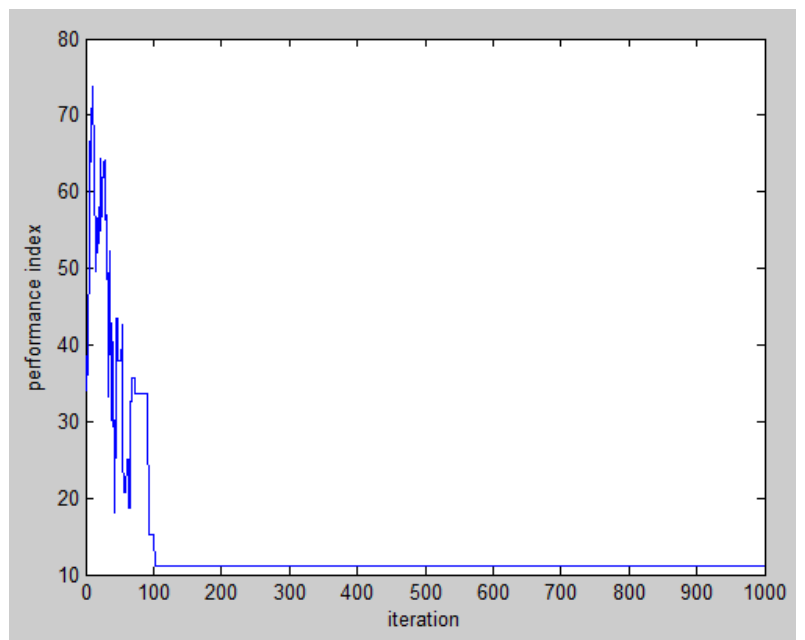

Figure 8: Optimization of Simulated Annealing process in LQT with Nonlinear Tracking

When the optimal weight matrices are used in LQT simulation, the results can be seen in Figure 9 and Figure 10. Reference functions applied are:

$$
\begin{aligned}
& r e f\left(\theta_{1}\right)=\sin (t) \\
& \operatorname{ref}\left(\theta_{2}\right)=\cos (t)
\end{aligned}
$$

Figure 9(a) is state solution of LQT with nonlinear (sinus) tracking in $\theta_{1}$ (angle of shoulder joint). Figure 9(b) is state solution of LQT with nonlinear (cosinus) tracking in $\theta_{2}$ (angle of elbow joint). Both angle of shoulder joint and elbow joint can follow the reference function.

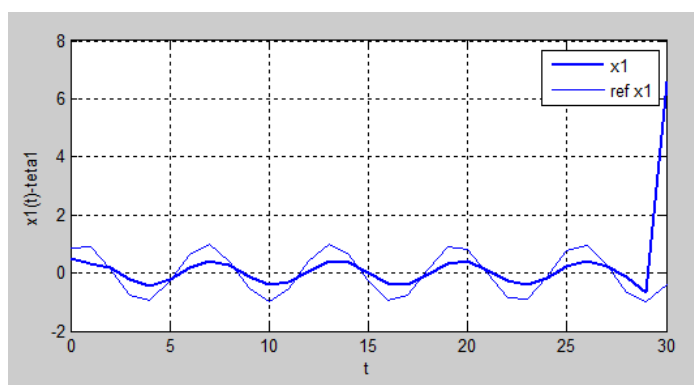

(a)

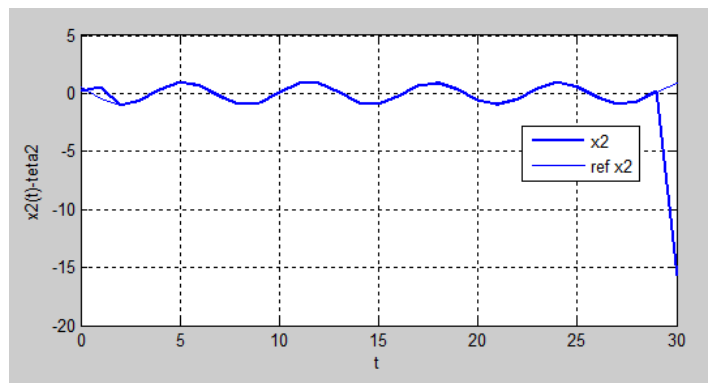

(b)

Figure 9: State Solutions of LQT with Nonlinear Tracking (a) Angle 1 (b) Angle 2

Figure 10 shows the results of six optimal controls from six muscle force vectors (in Newton) such as pectoralis major $U_{1}$, posterior deltoid $U_{2}$, brachialis $U_{3}$, triceps brachii (lateral head) $U_{4}$, biceps brachii $U_{5}$, and triceps (longhead) $U_{6}$.

In about around of final time, there are deviations on the optimal controls and state solutions because there are no optimization process of weight matrix $P$ in the performance index and weight matrix $P$ is assumed by 0 . 

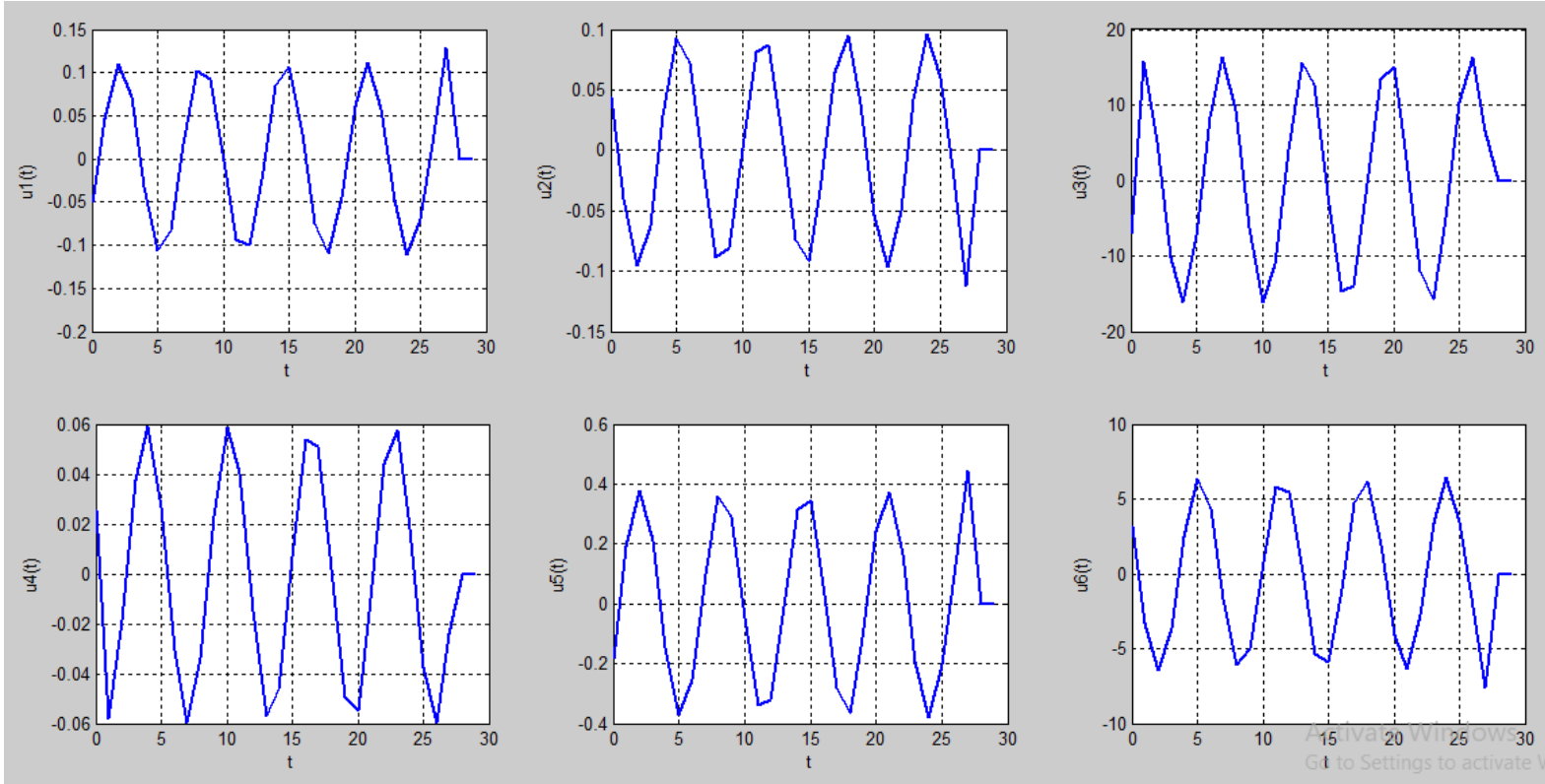

Figure 10: Six Optimal Controls from Six Muscle Force Vectors

\section{Conclusion}

In LQT, the value of performance index depends on the weight matrices so that we should optimize the weight matrices. Based on simulation results, Simulated Annealing can optimize the weight matrices in LQT so that it yields optimal performance index with angle as state solution following the reference and we also obtain optimal controls from six muscle forces applied.

The developments of this research are making translation movement such as position, velocity in state space model.

\section{References}

Hassani, K. and Lee, W. S. (2014) 'Optimal tuning of linear quadratic regulators using quantum particle swarm optimization' in Proceedings of the Int. Conference of Control, Dynamic System, and Robotics, Canada.

Karthick, S., Jerome, J., Kumar, E.V., and Raaja, G. (2016) 'APSO based weighting matrices selection of LQR applied to tracking control of SIMO system' in Proceedings of $3^{\text {rd }}$ International Conference on Advanced Computing, Networking and Informatics, Smart Innovation, Systems and Technologies, India.

Herlambang, T., Rahmalia, D., and Yulianto, T. (2019) 'Particle Swarm Optimization (PSO) and Ant Colony Optimization (ACO) for optimizing PID parameters on Autonomous Underwater Vehicle (AUV) control system' in Journal of Physics: Conference Series 1211, Jember, Indonesia: ICCGANT.

Herlambang, T., Rasyid, R.A., Hartatik, S., and Rahmalia, D. (2017) 'Estimasi posisi mobile robot menggunakan metode Akar Kuadrat Unscented Kalman Filter (AK-UKF)', Technology Science and Engineering Journal, Vol. 1, No. 2: 140-146.

Herlambang, T., Muhith, A., Rahmalia, D., and Nurhadi, H. (2020) 'Motion optimization using modified kalman filter for invers kinematics based multi DOF arm robot', International Journal of Control and Automation, Vol. 13, No. 2: 64-71.

Kirkpatrick, S., Gelatt, C.D. and Vecchi, M.P. (1983) 'Optimization by simulated annealing', Science, Vol. 220: 671-680.

Lewis, F.L., Vrabie, D.L. and Syrmos, V.L. (2012) Optimal Control, New Jersey: John Wiley and Sons. 
Naidu, D.S. (2003) Optimal Control System, Florida: CRC Press.

Ogata, K. (2003) Modern Control Engineering, New Jersey: Prentice Hall.

Rahmalia, D. and Herlambang, T. (2017) 'Application ant colony optimization on weight selection of optimal control SEIR epidemic model' in Proceeding of 7th Annual Basic Science International Conference, Malang, Indonesia: BASIC.

Rahmalia, D. and Herlambang, T. (2018) 'Weight optimization of optimal control influenza model using artificial bee colony’, International Journal of Computing Science and Applied Mathematics, Vol. 4, No. 1: 27-31.

Rahmalia, D. (2019) 'Optimisasi matriks bobot pada Linear Quadratic Regulator (LQR) inverted pendulum menggunakan ant colony optimization', Math Vision, Vol. 1, No. 2: 61-66.

Rao, S. S. (2009) Engineering Optimization Theory and Practice, New Jersey: John Wiley and Sons.

Zadravec, M., Matjacic, Z. (2013) 'Planar arm movement trajectory formation: An optimization based simulation study', Biocybernetics and Biomedical Engineering, Vol. 33: 106-117. 